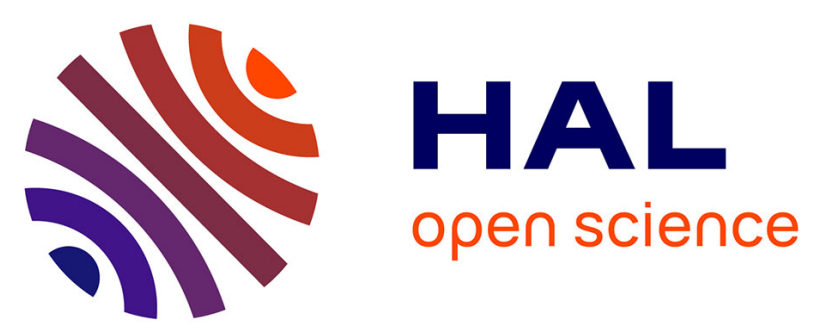

\title{
The Effect of Extrusion Conditions and Material Properties on the Gas Permeation Properties of LDPE/LLDPE Silage Wrap Films
}

Gerry M. Mcnally, Christopher Laffin, P. D. Forristal, Padraig O'Kiely, Christopher M. Small

\section{To cite this version:}

Gerry M. Mcnally, Christopher Laffin, P. D. Forristal, Padraig O'Kiely, Christopher M. Small. The Effect of Extrusion Conditions and Material Properties on the Gas Permeation Properties of LDPE/LLDPE Silage Wrap Films. Journal of Plastic Film and Sheeting, 2005, 21 (1), pp.27-38. $10.1177 / 8756087905052770$. hal-00572055

\section{HAL Id: hal-00572055 https://hal.science/hal-00572055}

Submitted on 1 Mar 2011

HAL is a multi-disciplinary open access archive for the deposit and dissemination of scientific research documents, whether they are published or not. The documents may come from teaching and research institutions in France or abroad, or from public or private research centers.
L'archive ouverte pluridisciplinaire HAL, est destinée au dépôt et à la diffusion de documents scientifiques de niveau recherche, publiés ou non, émanant des établissements d'enseignement et de recherche français ou étrangers, des laboratoires publics ou privés. 


\title{
The Effect of Extrusion Conditions and Material Properties on the Gas Permeation Properties of LDPE/LLDPE Silage WraP Films*
}

\author{
Gerry M. McNally, ${ }^{1, \dagger}$ Christopher Laffin, ${ }^{1}$ P. D. Forristal, ${ }^{2}$ \\ Padraig O'Kiely ${ }^{2}$ and Christopher M. Small ${ }^{1}$ \\ ${ }^{1}$ Polymer Processing Research Centre \\ The Queen's University of Belfast \\ Ashby Building, Stranmillis Road \\ Belfast, BT9 5AR, Northern Ireland \\ ${ }^{2}$ Teagasc, Oak Park \\ Carlow, Co. Meath, Ireland
}

\begin{abstract}
This study investigates the effect of extrusion processing conditions and comonomer type on the gas permeation properties of LLDPE films containing polyisobutylene (PIB). The results show improved gas barrier properties with increasing polymer density and with increases in film crystallinity and orientation as a result of extrusion processing conditions such as blow-up ratios.
\end{abstract}

KEY WORDS: LLDPE, LDPE, blends, PIB, $\mathrm{CO}_{2}$ permeability, crystallinity, orientation, shrinkage.

\section{INTRODUCTION}

S ILAGE IS A product formed when a material with a sufficiently high $\checkmark$ moisture content, such as grass, liable to spoilage by aerobic microorganisms, is stored anaerobically [1]. Silage making has its origins in antiquity, and in ancient times was probably undertaken mostly with grain intended for human consumption, as it affords a

\footnotetext{
*Note: This is expanded from a paper given at ANTEC 2004 in Chicago, Illinois; copyright SPE. †Author to whom correspondence should be addressed.
} 
means of storage in times of plenty for years when pestilence and bad weather led to poor harvests; it was also a method of concealing food from marauding tribes. In 1842, an account of the silage process as it is understood today was given by Watson and Smith [2]. The early development took place in France, up until the early 1900s. By 1920, Professor Virtanen had begun experiments on the effectiveness of mineral acids as treatments for rapidly reducing the $\mathrm{pH}$ to stem post-harvest losses, particularly of protein, in grass silage. The experimentation led to a predictable process known as the AIV process [3]. Problems arose due to the ingestion of mineral acids, resulting in unhealthy stock, and by the 1960s, the AIV method was out of favor with the introduction of formic acid as a treatment for the direct acidification of silage crops.

It was during the early 1980 s that baled silage was originally being produced by placing the bales inside black polyethylene bags. By 1984-85 the process of wrapping bales with stretch film was launched on a large scale in the UK and Ireland. Over the following years balewrapping machinery improved, leading to the latest generation of fully automated wrappers. Baled silage is now made on $80 \%$ of farms in Ireland, accounting for one-third of the total national tonnage amounting to about 9 million bales annually [4]. Other countries into which bale-wrapping has been more recently introduced are now, in turn, experiencing a tremendous growth in the popularity of this unique and innovative system, with 761 million kilograms of plastic resin used annually in the USA [5]. The use of baled silage has grown to such an extent that it is the primary conservation system on smaller sized farms and a secondary system on larger farms.

Given the widespread use of baled silage, it is vitally important that the film used possesses good gas barrier properties as well as good mechanical properties. The most common method of manufacture of silage films is by blown film and cast film extrusion of blends of low density and linear low density polyethylene (LDPE/LLDPE) resins. Both cast and blown film extrusions have their advantages and disadvantages with respect to the desired film properties, such as efficiency and ease of processability, etc., as shown by studies already carried out in this area [6-8]. However, very little work has been carried out with regard to the effect of processing conditions on the gas permeation properties of films intended for use in baled silage. This study investigates the effect of manufacturing conditions and material properties with varying concentrations of PIB on the air permeation properties of such LDPE/LLDPE films for use in baled silage application. 
Table 1. Properties of resins used in the manufacture of films.

\begin{tabular}{|c|c|c|c|c|}
\hline Material type & Producer & Comonomer & Density $\left(\mathrm{g} / \mathrm{cm}^{3}\right)$ & MFI (g/10 min) \\
\hline LLDPE & Dow & Octene & 0.919 & 1.1 \\
\hline LDPE & Dow & $\mathrm{N} / \mathrm{A}$ & 0.924 & 0.8 \\
\hline PIB & Polytechs & $\mathrm{N} / \mathrm{A}$ & 0.912 & $200-300$ \\
\hline Masterbatch & \multicolumn{4}{|c|}{$[52 \pm 2 \%$ PIB in above LLDPE] } \\
\hline
\end{tabular}

Table 2. Properties of LLDPE portion of LLDPE-LDPE (70/30) blends.

\begin{tabular}{lccccc}
\hline Notation & Manufacturer & Grade & Comonomer & Density $\left(\mathbf{g} / \mathbf{c m}^{\mathbf{3}}\right)$ & MFI (g/10 $\mathbf{~ m i n})$ \\
\hline A & Exxon & ML4518 & Hexene & 0.918 & 4.5 \\
B & Exxon & ML2518 & Hexene & 0.918 & 2.5 \\
C & BASF & 18RFA & Hexene & 0.918 & 2.5 \\
D & BASF & 18FAX & Hexene & 0.918 & 1.1 \\
E & Dow & 5200 & Octene & 0.917 & 4.0 \\
F & Dow (ZN) & NG5056E & Octene & 0.919 & 1.1 \\
G & Dow & SL4102 & Octene & 0.903 & 1.5 \\
H & Dow & 5100 & Octene & 0.920 & 0.85 \\
I & BASF & $0332 \mathrm{H}$ & Butene & 0.905 & 1.0 \\
\hline
\end{tabular}

\section{EXPERIMENTAL}

\section{Materials}

The materials used in this study are shown in Tables 1 and 2. Films manufactured from materials shown in Table 1 were processed as a blend due to previously reported problems associated with blown film extrusion of LLDPE, such as bubble instability and random bubble distortion $[9,10]$. Therefore, films were produced using an LLDPELDPE blend (70/30: w/w), containing $0,1,2,3$, and $4 \%$ PIB as introduced through the Masterbatch described in Table 1. Films manufactured from materials shown in Table 2 were produced by the cast film extrusion process, and again were manufactured using an LLDPE-LDPE blend (70/30: w/w), for a direct comparison, containing 0 and 4\% PIB (Table 1). All films were manufactured from mLLDPEs with the exception of film $\mathrm{F}$ that used a Ziegler-Natta LLDPE.

\section{Preparation of Films}

The blown films were manufactured using a Killion-KN150 $38 \mathrm{~mm}$ extruder with a general purpose screw $(L / D=30,3: 1$ compression 
ratio), connected to a $75 \mathrm{~mm}$ diameter annular die with a die gap of $800 \mu \mathrm{m}$. The temperature profile of the barrel was increased from $195^{\circ} \mathrm{C}$ at the feed section to $210^{\circ} \mathrm{C}$ at the die. A single orifice cooling ring was used to cool the melt upon exit from the die. The screw speed was set at $20 \mathrm{rpm}$, with the haul-off adjusted to produce films of $25 \mu \mathrm{m}$ nominal thickness while using a blow-up ratio (BUR) of 1.5 with neat resin. The same speed settings were then maintained while changing BUR and percentage PIB. Blow-up ratios of 1.5, 2.0, and 2.5 were used to manufacture the films.

Cast films were manufactured using a Killion cast film extrusion system which was fitted with a $600 \mathrm{~mm}$ wide flexible lip sheet die, with a die gap set at $250 \mu \mathrm{m}$. The barrel temperature was increased from $200^{\circ} \mathrm{C}$ at the feed section to $220^{\circ} \mathrm{C}$ at the die. A constant screw speed of $30 \mathrm{rpm}$ was used with a maintained chill roll temperature of $\approx 15^{\circ} \mathrm{C}$ and an air gap of $110 \mathrm{~mm}$. A rubber-coated roller was used to press the hot film extrudate onto the chill roll. A nominal thickness of $25 \mu \mathrm{m}$ film was obtained for resin A, 0\% PIB, with a haul-off ratio of 1.04 and nip roll speed of $7.0 \mathrm{~m} / \mathrm{s}$; these processing parameters were then maintained to produce all other films with the resulting thicknesses being reported.

\section{Permeation Testing}

A Davenport gas permeability measuring apparatus was used to determine the gas transmission rate (GTR) (permeability) of film samples. The apparatus was designed for direct measurement of the GTR through plastic films in accordance with B.S.2782, method 821A, ASTM D-1434 and similar methods. The test gas used was $\mathrm{CO}_{2}$ (99.8\% purity) using a specimen area of $23.8 \mathrm{~cm}^{2}$.

\section{Differential Scanning Calorimetry (DSC)}

This analysis was carried out using a Perkin-Elmer DSC-6 with samples heated from 30 to $140^{\circ} \mathrm{C}$ at a rate of $10^{\circ} \mathrm{C} / \mathrm{min}$. The latent heat $(\Delta \mathrm{H} ; \mathrm{J} / \mathrm{g})$ was calculated for each sample.

\section{Shrinkage Analysis}

Shrinkage analysis was carried out in accordance with ASTM D2732. A circular test sample of $50 \mathrm{~mm}$ diameter was cut and its orientation with respect to the manufacturing process was marked. It was then lightly coated with silicone oil and placed on a hot plate at $130^{\circ} \mathrm{C}$ for $75 \mathrm{~s}$, after which it was measured to determine the shrinkage. 


\section{RESULTS AND DISCUSSION}

\section{Permeation Testing}

The effect of extrusion conditions and PIB concentration on the $\mathrm{CO}_{2}$ permeation properties of the films are shown in Figures 1 and 3, with the effect of material properties on the gas permeation properties shown in Figures 2 and 4. Figures 1 and 2 show the gas transmission rates of the films, with the film thicknesses shown in Tables 3 and 4 .

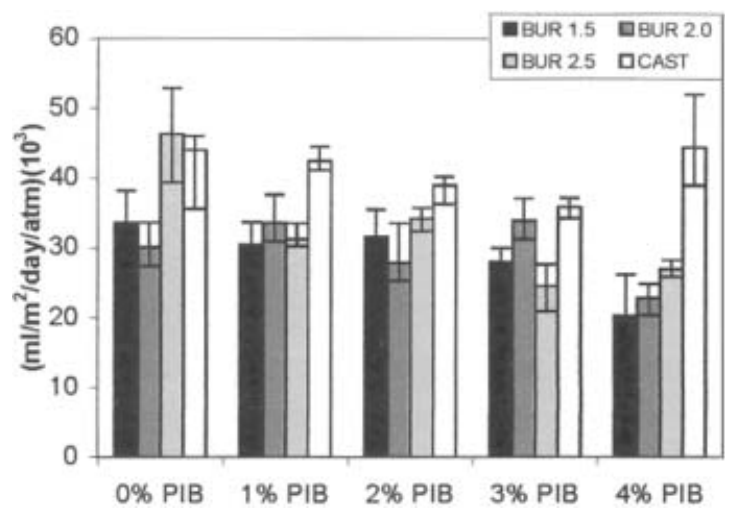

Figure 1. $\mathrm{CO}_{2}$ gas transmission rates at room temperature for films manufactured by blown film extrusion using different processing conditions with a 70/30 blend of LLDPE-LDPE.

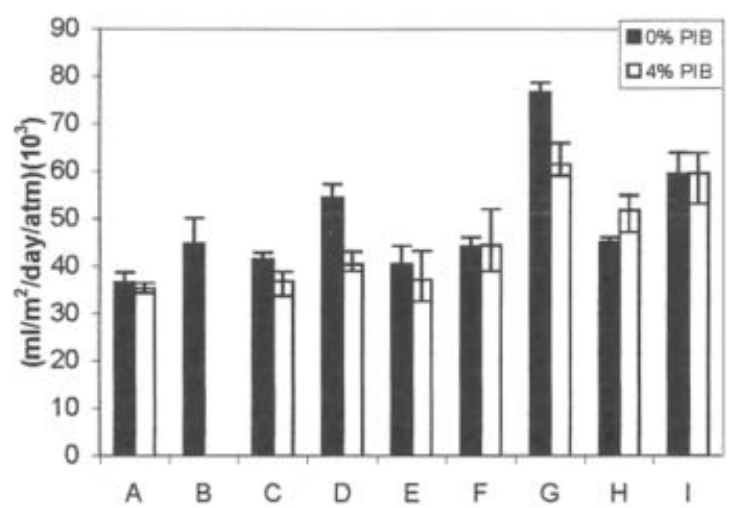

Figure 2. $\mathrm{CO}_{2}$ gas transmission rates at room temperature for films manufactured by cast extrusion from different materials. 


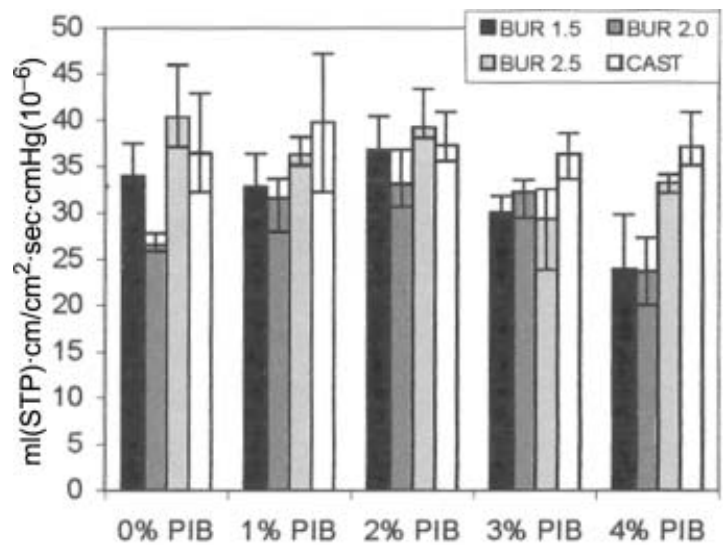

Figure 3. $\mathrm{CO}_{2}$ permeation coefficient at room temperature for films manufactured by blown film extrusion using different processing conditions with a 70/30 blend of LLDPE-LDPE.

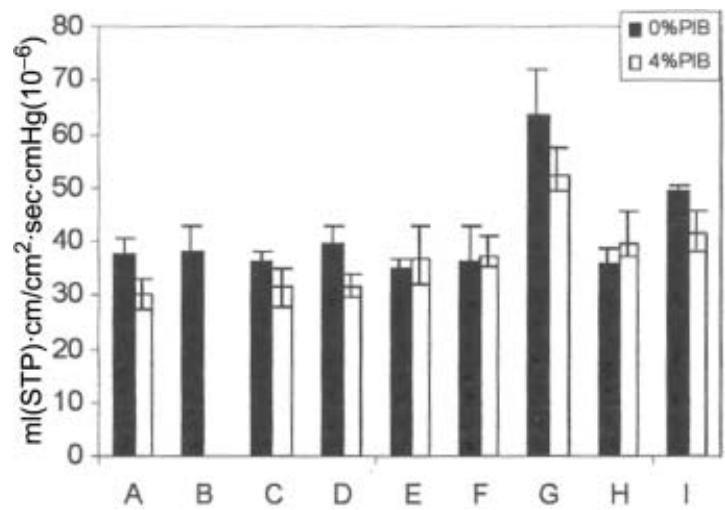

Figure 4. $\mathrm{CO}_{2}$ permeation coefficient at room temperature for films manufactured by cast extrusion from different materials.

Table 3. Effect of PIB and BUR on thickness $(\mu \mathrm{m})$ of films made at standard settings.

\begin{tabular}{lccccc}
\hline & 0\% PIB & 1\% PIB & 2\% PIB & 3\% PIB & 4\% PIB \\
\hline BUR $=1.5$ & 25.8 & 27.4 & 29.8 & 27.4 & 29.6 \\
BUR $=2.0$ & 22.6 & 24.0 & 30.6 & 24.25 & 26.4 \\
BUR $=2.5$ & 22.4 & 29.6 & 29.2 & 30.4 & 31.6 \\
CAST & 21.2 & 23.8 & 25.8 & 25.4 & 21.4 \\
\hline
\end{tabular}


Table 4. Effect of 0 and $4 \%$ PIB on the thickness $(\mu \mathrm{m})$ of different resin blends using cast film system with constant extrusion conditions.

\begin{tabular}{cccccccccc}
\hline & A & B & C & D & E & F & G & H & I \\
\hline $0 \%$ PIB & 26.2 & 21.6 & 22.0 & 18.4 & 21.8 & 21.2 & 20.4 & 20.0 & 19.6 \\
$4 \%$ PIB & 24.0 & & 21.4 & 19.4 & 24.0 & 21.4 & 21.4 & 20.0 & 18.4 \\
\hline
\end{tabular}

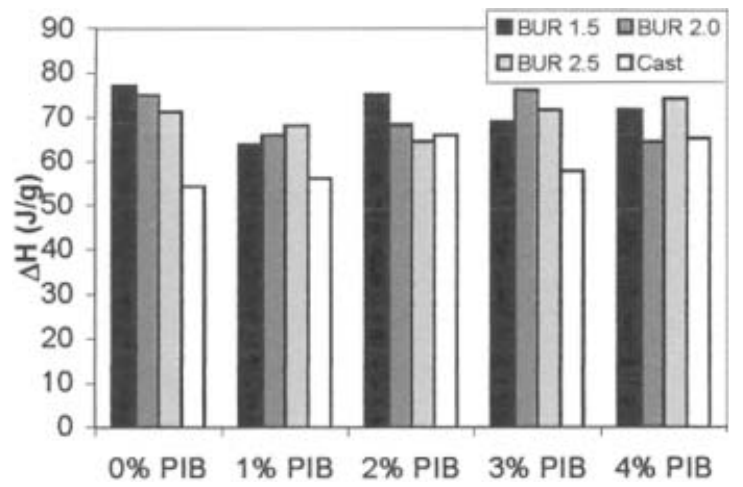

Figure 5. Crystallinity of films manufactured by blown film extrusion using different processing conditions with a 70/30 blend of LLDPE-LDPE.

The results in Figures 1 and 3 show that there is no significant correlation between PIB content and the change in $\mathrm{CO}_{2}$ transmission rate and permeation coefficient for these films. This is particularly noticeable for films manufactured by cast extrusion. It is also evident that the manufacturing conditions do have an affect on the permeation properties of the films since changes in manufacturing conditions may cause changes in crystallinity (Figure 5) and orientation of the films, which has been previously reported [11].

The results in Figures 2 and 4 show that the films A-D, manufactured from materials of the same density but different MFI, have similar permeation properties indicating that the MFI of the material does not affect the permeation properties of the film. However, it is clear from the lower density films, G and I, that the density of the material has a significant affect on the permeation property of the film.

For films A-D, manufactured from hexene copolymers, the results showed that the gas transmission rate and permeation coefficient is reduced by the presence of $4 \%$ PIB. The results also show a similar trend for films manufactured from low density material, films G and I. 


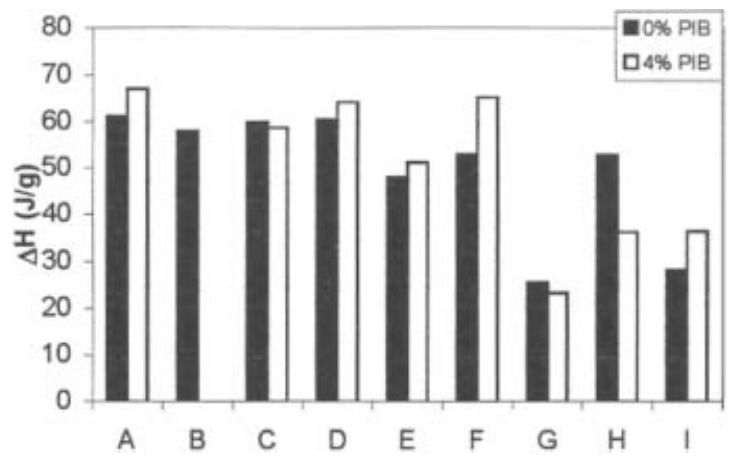

Figure 6. Crystallinity of films manufactured by cast extrusion from different materials.

Tests on films $\mathrm{E}, \mathrm{F}$, and $\mathrm{H}$, manufactured from octene-based resins, showed no relationship between PIB content and the permeation coefficient.

The gas transmission rates for all films tested showed good agreement with previous reports for $25 \mu \mathrm{m}$ polyethylene film [12].

\section{Differential Scanning Calorimetry (DSC)}

The effect of extrusion conditions and PIB concentration on the crystallinity of the films is shown in Figure 5, and the effect of material properties on the crystallinity of the films is shown in Figure 6.

The results in Figure 5 show that films manufactured by the cast extrusion process exhibit lower crystallinity than those manufactured by blown film extrusion, as a result of improved quenching of the film during manufacture due to good contact between the melt and the chill rolls. Crystallinity of the cast films showed a slight increase with increasing PIB content. Films manufactured using blown film extrusion show little correlation between blow-up ratio and crystallinity; this is also reflected in the $\mathrm{CO}_{2}$ permeation properties of the films.

Figure 6 shows that the material density has an affect on the crystallinity of the films produced. Figures 2 and 4 show that films with higher crystallinity exhibit improved gas barrier properties, and that films A, D, and I showed increased crystallinity with the presence of PIB and thus improved gas barrier properties. The orientation of these films has been previously investigated [11], showing that films manufactured from octene copolymers showed a higher degree of orientation in the machine direction than the transverse direction, while films manufactured from hexene and butene copolymers exhibited similar orientation 
in both directions. Therefore, these results show that comonomer type and PIB content have an affect on the crystallization of the film.

\section{Shrinkage Analysis}

Figure 7 shows the results of shrinkage analysis $\left(130^{\circ} \mathrm{C}\right)$ carried out on films manufactured using different extrusion processing conditions, and Figures 8 and 9 show the results of shrinkage analysis carried out on films manufactured from different materials, containing 0 and $4 \%$ PIB, respectively.

From shrinkage analysis on all films it was shown that the greatest shrinkage was exhibited in the machine direction. The results in Figure 7 show that films manufactured from cast extrusion exhibit

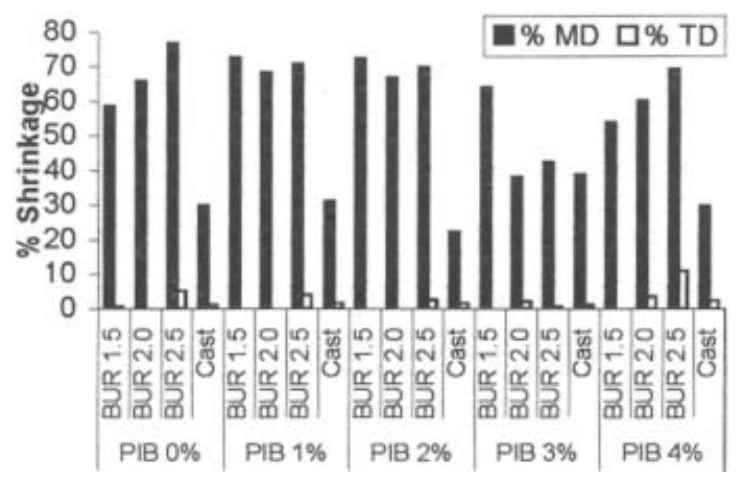

Figure 7. Shrink characteristics of films manufactured by blown film extrusion using different processing conditions with a 70/30 blend of LLDPE-LDPE at $130^{\circ} \mathrm{C}$.

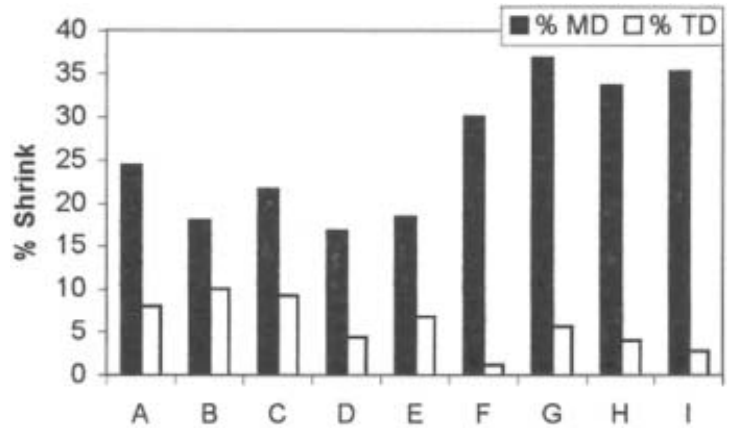

Figure 8. Shrink characteristics of films manufactured by cast extrusion from different materials containing $0 \%$ PIB at $130^{\circ} \mathrm{C}$. 


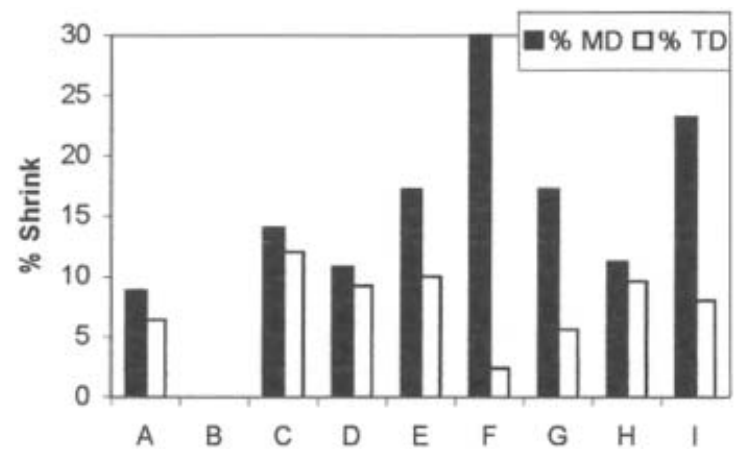

Figure 9. Shrink characteristics of films manufactured by cast extrusion from different materials containing $4 \% \mathrm{PIB}$ at $130^{\circ} \mathrm{C}$.

less shrinkage in comparison to films manufactured from blown film extrusion in both directions. For films containing 0 and $4 \%$ PIB, it was shown that as the BUR increases the shrinkage of the film increases, although with 1-3\% PIB, no consistent effect of BUR was noted.

Figure 8 shows that films manufactured from octene copolymers exhibit a greater difference in shrinkage characteristics between machine and transverse directions indicating a greater degree of orientation in the machine direction. The results in Figure 9 also show that the addition of PIB reduces the degree of orientation of the films; this was more noticeable in films manufactured from hexene copolymers. The orientation of these films has been previously investigated [11], showing that films manufactured from octene copolymers showed a higher MD/TD orientation than was obtained with hexene copolymers.

\section{CONCLUSIONS}

This study investigated the effect of processing conditions, resin properties, and PIB content on the $\mathrm{CO}_{2}$ permeation properties of films. Permeation analysis of the various films showed that extrusion processing conditions affected the $\mathrm{CO}_{2}$ permeation properties of the films. These changes in barrier performance may be attributed to changes in crystallinity, shown in Figure 5, and orientation induced by processing which has been previously reported [11].

The results also show that the MFI of the material had little or no effect on the $\mathrm{CO}_{2}$ permeation properties of the various films. Polymer 
density was shown to have the most significant effect on barrier performance, with materials of low density having significantly poorer gas barrier properties than materials of a higher density.

For films manufactured with octene copolymer, the results show that the concentration of PIB had no significant effect on the gas barrier properties of these films. However, films manufactured from hexene and butene copolymers showed a decrease in $\mathrm{CO}_{2}$ permeation coefficient and increased crystallinity with increasing concentration of PIB. DSC analysis showed that materials with higher densities were more crystalline, and that they exhibited improved gas barrier properties. Shrinkage analysis at $130^{\circ} \mathrm{C}$ showed that films manufactured from octene copolymers exhibited a greater degree of orientation, and incorporation of $4 \%$ PIB reduced orientation of the films; this was particularly noticeable for films manufactured from hexene copolymers. The greater degree of orientation of octene films was also shown to reduce the gas permeation coefficient.

\section{REFERENCES}

1. Woolford, M.K. (1984). The Silage Fermentation, Marcel Dekker, New York.

2. Watson, S.J. and Smith, A.M. (1956). Silage, 200th edn, p. 144, Crosby Lockwood, London.

3. Virtanen, A.I. (1933). Empire Journal of Experimental Agriculture, 1: $143-155$.

4. O'Kiely, P., Forristal, P.D., Lenehan, J.J., Fuller, H., Brady, K. and Barlow, M. (1998). Farm and Food, 8(3): 29-32.

5. Amidon Recycling, American Plastics Council (1994)

6. Bilham, M., Clarke, A.H., Garrett, G. and Murphy, W.R. ANTEC 2001 Proceedings, pp. 96-100.

7. Degroot, J.A, Doughty, A.T., Stewart, K.B. and Patel, R.M. (1994). J. Appl. Polym. Sci., 52: 365-376.

8. Began, C.M., McNally, G.M. and Murphy, W.R. ANTEC 1999 Proceedings, pp. $90-94$.

9. Field, G.J., Micic, P. and Bhattacharya, S.N. (1999). Polymer Int., 48: 461-466.

10. Micic, P. and Bhattacharya, S.N. (2000). Polymer Int., 49: 1580-1589.

11. Small, C.M., McNally, G.M., Marks, A. and Murphy, W.R. ANTEC 2002 Proceedings, pp. 230-234.

12. Briston, J.H. (1983). Plastics Films, 2nd edn, p. 362, The Plastics and Rubber Institute, New York. 


\section{BIOGRAPHIES}

\section{Christopher Laffin}

Christopher Laffin is a third year PhD student at the PPRC in the Queen's University of Belfast, Northern Ireland. He was awarded a B.Eng (Honours) degree in Mechanical Engineering and an MSc in Polymer Engineering, both from the Queen's University of Belfast. His current research is concerned with properties of polymer films for silage wrap applications.

\section{Gerry M. McNally}

Gerry McNally is a Senior Lecturer in Engineering Materials in the School of Chemical Engineering at the Queen's University of Belfast. He has 12 years industrial experience at the senior management level in polymer extrusion. He is a founder member of the Polymer Processing Research Centre (PPRC) and was made the Director in 2004. His expertise is in various areas of processing of polymers and their additives. He has been, and is, the lead academic supervisor in 15 polymer-related TCS Programmes, one of which was awarded the Best TCP in 1999. He has published over 175 papers and international conference proceedings.

\section{Christopher M. Small}

Christopher Small was awarded a B.Eng (Honours) degree in Mechanical Engineering and an MSc (with distinction) in Polymer Engineering, both from the Queen's University of Belfast. He went on to complete his $\mathrm{PhD}$ in "Investigating the effects of manufacturing variables on the properties and performance of polyethylene stretch and cling films."

\section{Padraig O’Kiely}

Padraig O'Kiely obtained his MAgrSc and $\mathrm{PhD}$ from the National University of Ireland at University College Dublin. He is a research scientist (forage conservation and beef nutrition) and Head of the Beef Production Department with Teagasc at its national beef research centre in Grange, Co. Meath. 